Published online 2017 April 13.

Abstract

\title{
Radiofrequency Ablation of Benign Thyroid Nodules: Initial Clinical Experience in Iran
}

\author{
Hojat Ebrahiminik, ${ }^{1,}$ Ali Mosaddegh khah, ${ }^{2}$ Ahmadreza Soroush, ${ }^{3}$ Narges Fadaei, ${ }^{4}$ Babak Shekarchi, ${ }^{5}$ \\ and Noor Fattah ${ }^{6}$ \\ ${ }^{1} \mathrm{MD}$, Interventional Radiologist, Assistant Professor of Radiology, AJA University of Medical Sciences, Tehran, Iran \\ ${ }^{2} \mathrm{MD}$, Endocrionologist, AJA University of Medical Sciences, Faculty of Medicine \\ ${ }^{3} \mathrm{MD}$, General Surgeon, Professor of General Surgery, Shariati Hospital \\ ${ }^{4} \mathrm{MD}$, General physician \\ ${ }^{5} \mathrm{MD}$, Radiologist, Associated Professor of Radiology, AJA University, Emam Reza Hospital Imaging Center \\ ${ }^{6}$ Resident of General Surgery Ward, Shariati Hospital \\ "Corresponding author: Hojat Ebrahiminik, MD, Interventional Radiologist, Assistant Professor of Radiology, AJA University of Medical Sciences, Tehran, Iran. E-mail: \\ dr_ebrahiminik@yahoo.com
}

Received 2016 December 21; Accepted 2017 February 08.

\begin{abstract}
Prevalence of thyroid nodules diagnosed by ultrasonography has been reported to be high (about 50\%) probably due to iodine deficiency in our region. Most thyroid nodules benign but some require treatment for cosmetic reasons or subjective symptoms. The conventional method of treatment in Iran is surgery. For the first time in Iran, from February 2016, 50 patients with 63 nodules (solid or cystic) were successfully treated by radiofrequency (RF) ablation. The procedure was performed under local anesthesia with no need for hospitalization. At one and three months post-ablation follow ups $40 \%$ to $67 \%$ reduction in nodule volume was observed. No hormone imbalance or voice changes were seen in none of the patients. Indication of RF ablation includes benign confirmed nodules (at least 2 times Fine needle aspiration or biopsy) neck pain, dysphasia, foreign body sensation, discomfort, cough, cosmetic problems, or thyrotoxicosis in cases of autonomously functioning thyroid nodules (AFTNs). Compared with surgery, RF ablation as a minimally invasive approach provided significantly lower rate of complications regarding thyroid function which well-maintained after procedure also no external scar was formed. Pain and inflammation during the first 3 to 7 days after RF ablation and long term treatment results (1 to 6 months) are of disadvantages. We recommend RF ablation to be considered as possibly the first-line treatment for benign thyroid nodules. Disclosure: Nothing to disclose.
\end{abstract}

Keywords: Thyroid Nodule, Radio Frequency, Ablation, Iran, RF

This is an abstract presented in the 33rd Iranian congress of radiology (ICR) and the 15th congress of Iranian radiographic science association (IRSA). 